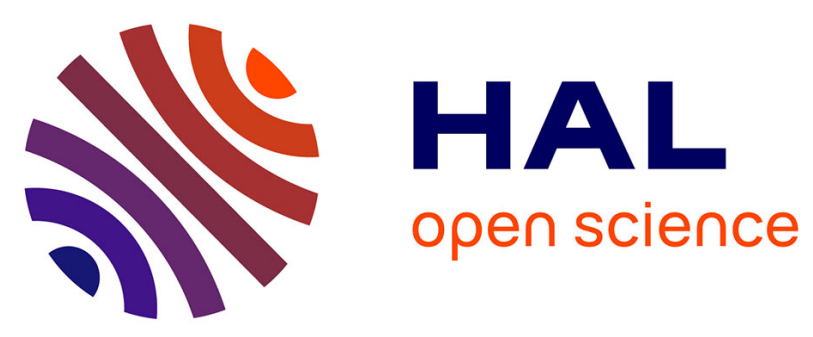

\title{
The cervicofacial lift under pure local anaesthesia diminishes the incidence of post-operative haematoma
}

Vivien Moris, Pierre Bensa, Brice Gerenton, Philippe Rizzi, Sarah Cristofari, Narcisse Zwetyenga, David Guilier

\section{- To cite this version:}

Vivien Moris, Pierre Bensa, Brice Gerenton, Philippe Rizzi, Sarah Cristofari, et al.. The cervicofacial lift under pure local anaesthesia diminishes the incidence of post-operative haematoma. Journal of Plastic, Reconstructive and Aesthetic Surgery, In press, 10.1016/j.bjps.2018.10.046 . hal-02063497

\section{HAL Id: hal-02063497 \\ https://u-bourgogne.hal.science/hal-02063497}

Submitted on 22 Oct 2021

HAL is a multi-disciplinary open access archive for the deposit and dissemination of scientific research documents, whether they are published or not. The documents may come from teaching and research institutions in France or abroad, or from public or private research centers.
L'archive ouverte pluridisciplinaire HAL, est destinée au dépôt et à la diffusion de documents scientifiques de niveau recherche, publiés ou non, émanant des établissements d'enseignement et de recherche français ou étrangers, des laboratoires publics ou privés.

\section{(ㄷ)(1) $\$$}

Distributed under a Creative Commons Attribution - NonCommercial| 4.0 International 


\section{The Cervicofacial lift under Pure local anaesthesia diminishes the incidence of postoperative haematoma}

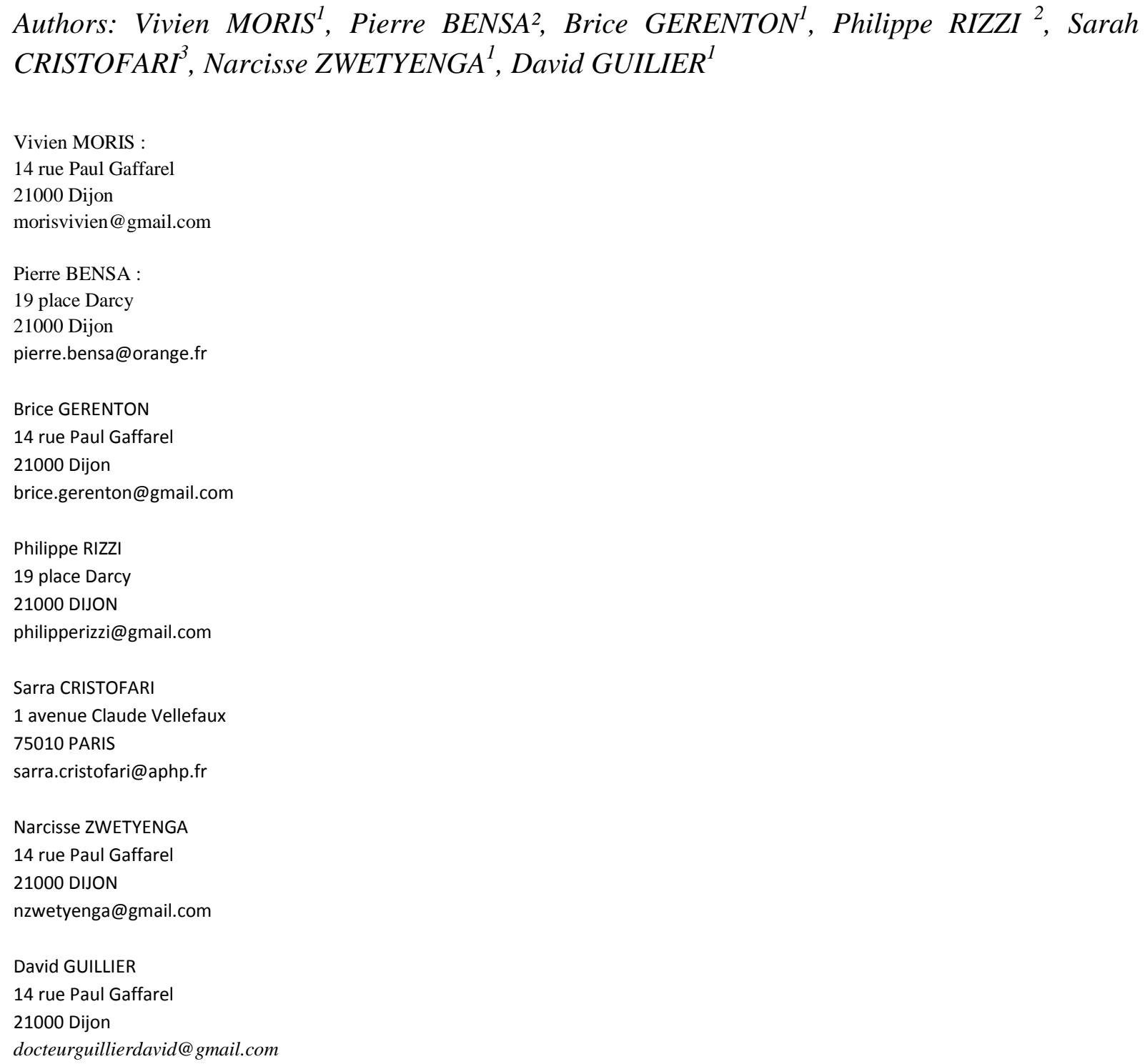

${ }^{3}$ :Service de chirurgie plastique, CHU Saint Louis, 1 avenue Claude Vellefaux 75010 PARIS 


\section{Abstract}

The cervicofacial lift is a frequently performed procedure in plastic surgery. It is the reference technique for facial rejuvenation and restoration of the oval form of the face and it is essential to treat excess skin. One of the most frequent complications of this procedure is the formation of haematomas. The aim of this article is to analyze the incidence of bleeding in the standard cervicofacial lift carried out under pure local anaesthesia. The entire operation, including liposuction and tightening of the SMAS, can be done under local anaesthesia. A total of 1500 patients, who have undergone cervicofacial lift under pure local anaesthesia between November 1995 and January 2016, were included in the study. The incidence of early bleeding (in the first 15 days following the operation) was recorded and analyzed. Pre- intra- and postoperative monitoring of the arterial blood pressure revealed stable pressure in the peri-operative period. The mean difference in blood pressure when comparing the intraoperative to the postoperative periods was $7 \mathrm{mmHg}$ for the systolic $\mathrm{BP}$ [range from 3 - 25] and $4 \mathrm{mmHg}$ [range from 2 - 12] for the diastolic BP, with lower mean values in the postoperative period. We identified nine bleeding events in 1500 patients $(0.6 \%)$ The cervicofacial lift under pure local anaesthesia does not radically modify the surgical technique. It allows better control of arterial blood pressure of patients throughout the surgical procedure and avoids fluctuations in blood pressure, which is one of the main causes of bleeding and haematoma formation. The infiltration of xylocaine adrenaline combined with the absence of hypotensive general anaesthesia diminishes the incidence of haematoma and ensures an early return home for the patients. 


\section{Introduction}

The cervicofacial lift is a frequent and useful intervention. Despite the popularity of new techniques for rejuvenation of the face, such as Botox, fillers, lipofilling (1) and suspension sutures, the "traditional" cervicofacial lift is the only technique available to plastic surgeons to remove the inevitable excess skin that appears with age (2).

The standard cervicofacial lift consists of tightening the skin and the superficial musculoaponeurotic system (SMAS). This procedure on the muscle and skin can durably eliminate wrinkles in the lower third of the face and the neck. The excess skin which arises from the tightening of the SMAS is removed by surgery. Liposuction is generally performed in the area under the chin and the neck to treat the unattractive "double-chin". In most cases, this operation is carried out under general anaesthesia, less commonly under sedation combined with local anaesthesia and exceptionally under pure local anaesthesia without using any systemic muscle relaxants or anxiolytic drugs. One of the most feared complications is the onset of postoperative haematoma as it starves the skin of oxygen and can potentially cause skin necrosis. The onset of haematoma after a cervicofacial lift correlates with the patient's pre- intra- and postoperative arterial blood pressure $(3,4)$.

The aim of this article was to analyze the incidence of bleeding following a standard cervicofacial lift (5-7) carried out under pure local anaesthesia. 


\section{Materials and Methods}

\section{Patients:}

From November 1995 to January 2016, 1500 patients who underwent a cervicofacial lift under pure local anaesthesia were included.

\section{Inclusion:}

The indication for a cervicofacial lift with tightening of the SMAS under local anaesthesia was proposed by the surgeon following two consultations. The shape and volume of the face as well as the quality of the skin (tension and elasticity) were taken into consideration.

\section{Exclusion:}

Smokers $>5$ cigarettes a day were excluded, as were persons with skin disorders (Xeroderma pigmentosum, sclerodermia, lupus...) or with body dysmorphia disorder. Associated surgery of the face was also excluded (mask lift, forehead lift, rhinoplasty). Only blepharoplasties associated with the cervicofacial lift were not excluded. Patients treated with anticoagulants (oral or injectable) or antiplatelets (aspirin, plavix) were excluded.

\section{Principal judgement criterion:}

The onset of an early bleeding event (in the 15 days following surgery) was recorded and analysed. Bleeding events were defined as a postoperative haematoma or active bleeding requiring draining (out-patient or operating room).

Pre-, intra-, and postoperative arterial blood pressure was continuously monitored (every 4 min). Surveillance was started $30 \mathrm{~min}$ before the start of the local anaesthesia and continued for 2 hours after the end of the surgery. 


\section{Secondary judgement criterion:}

Local complications were looked for: infection of the surgical site, wound dehiscence, facial paralysis and an asymmetric result.

Pain was evaluated using a Visual Analogue Scale and postoperative nausea was documented.

\section{Surgical procedure}

All patients underwent the same surgical procedure, a cervicofacial lift with a SMAS flap. No patients were given medication before the operation. . Neither anxiolytics, nor analgesics, nor anti-hypertensives were administered. A simple analgesic treatment with paracetamol and codeine was prescribed in the postoperative period. The first dose was taken 2 hours after the intervention before the patient returned home.

\section{Local anaesthesia:}

Local anaesthesia was administered once the preoperative marking had been done with patients standing or sitting. (Figure 1)

Patients were positioned in supine position with legs downwards to diminish arterial blood pressure in the head and neck. The injection sites were swabbed with chlorhexidine before local anaesthesia was injected.

The preparation for the local anaesthesia was a modification of the Klein formula (8):

- $250 \mathrm{cc}$ of injectable $\mathrm{NaCl} 0.9 \%$

- $\quad 80 \mathrm{ml}$ of xylocaine : $10 \mathrm{mg} / \mathrm{ml}$ with adrenaline $: 0.005 \mathrm{mg} / \mathrm{ml}$

- $\quad 10 \mathrm{ml}$ of naropeine $7.5 \mathrm{mg} / \mathrm{ml}$

Local anaesthesia was started with a syringe of $1 \mathrm{cc}$ and a 30 gauge needle and injections into key points: under the chin and around both ear lobes. These are the only three painful injections for the patient. Incisions were made at these key points using a $\mathrm{N}^{\circ} 15$ scalpel blade, and a Klein cannula was inserted. The diluted anaesthesia solution was thus infiltrated gently 
and atraumatically via a blunt-tipped cannula $100 \mathrm{~mm}$ in length and $1.25 \mathrm{~mm}$ in diameter manufactured by the French Aesthetic group. The solution was injected abundantly under the skin in the cheeks and in the pre-auricular, cervical and retro-auricular areas.

This first stage of the anaesthesia takes an average of 15 minutes. (Figures 2,3,4)

The solution is left to take effect for 10 minutes before the incision (time necessary for the adrenaline to create a bloodless field). In the meantime, the table is prepared and the $2^{\text {nd }}$ skin prep for the incision sites is done. The principal advantage of this technique is that patients can cooperate by raising their head, thus making it easier to place surgical drapes in aseptic conditions. Liposuction of the cervical area and under the chin is carried out via an incision under the chin and using a $\mathrm{N}^{\circ} 4$ cannula. Liposuction extracts the excess fat and prepares the dissection plane by creating dissection tunnels using the cannula. . (Figure 5)

A traditional lift with tightening of the SMAS was carried out using partial SMASectomy. The creation of a subcutaneous plane was facilitated by the hydrodissection and liposuction. The incision starts in the scalp behind the hairline and continues downwards passing in front of the ear so that the scar will be on the interior side of the tragus, it then passes under the lobe and continues behind the ear where it ends. The skin is lifted using skin hooks and undermining is first achieved by using a cold $\mathrm{N}^{\circ} 15$ scalpel blade and then using Metzenbaum scissors to cut along the infiltration tunnels but keeping a distance of $3 \mathrm{~cm}$ from the lip commissures. Haemostasis is achieved step-by-step using bipolar coagulation forceps.

Halstead forceps are used to pinch and pull the SMAS so as to identify useful traction vectors. The SMAS is elevated by two forceps and incised between them using a cold blade (Figure 6). This manoeuvre makes it possible to incise the SMAS without damaging the branches of the facial nerve. The sub-aponeurotic elevation is achieved using a swab held between forceps and completed with a chisel (Figure 7-8). The SMAS flap is pulled tight and sutured in the 
proximal position using 3-0 Vicryl sutures and respecting the lines of traction identified earlier.

The skin flaps are repositioned and the line of the skin resection is determined using a marker clamp. The skin is resected using a cold blade and iridectomy scissors starting with the retroauricular cervical flap (Figures 9 and 10). The subcutaneous suture using 3-0 Vicryl starts behind the ear on a Redon 6 French drain which will be left free in the dressing. This drain will be removed one day after the surgery. The pre-auricular skin resection is then done. Particular attention must be paid to the resection around the lobe, which has to be done under tension to obtain a natural-looking result.

The skin is sutured using Indermil-type glue. Neither running nor simple interrupted sutures should be used for the skin (Figures 11 and 12). Vaseline is applied to the wounds, which are then covered with compresses dampened with anaesthetic solution and held in place with 10cm-wide Velpeau bands. It is essential to check the position of the lobes once the dressing is in place to avoid necrosis of the lobe due to incorrect positioning of the dressing.

\section{Results:}

Patients characteristics (Table 1):

There were 1350 women and 150 men with a mean age of 58 years [40 - 69] (Table 1). It was the first surgery in 1394 patients, the second in 123 patients and the third in 50 patients. There were 510 smokers, who reduced the number of cigarettes or stopped smoking before the operation (maximum 5 cigarettes a day, 4 weeks before and 4 weeks after the intervention). Comorbidities included 311 patients with treated hypertension measured at > 130/80 during the anaesthesia consultation, and 120 patients with treated diabetes with $\mathrm{HbA} 1 \mathrm{c}<8 \%$.

The mean duration to perform the local anaesthesia was 15 minutes.

The mean duration of the surgery excluding the time of anaesthesia was 2 hours. 


\section{Principal Judgement Criterion:}

In the 1500 patients, there were nine bleeding events (0.6\%). All nine of these patients suffered from hypertension, measured at $>150 / 90$ during the anaesthesia consultation despite dual antihypertensive therapy.

The mean systolic blood pressure was $123 \mathrm{mmHg}$ [78 - 169] in the preoperative stage, 147 mmHg [88 - 178] during the procedure and it stabilized at $142 \mathrm{mmHg}$ [85 - 175] after surgery in the postoperative stage (figure 13).

Mean variations in blood pressure from the preoperative to the intraoperative stage were 22 mmHg [4 - 45] for systolic BP and $8 \mathrm{mmHg}$ [4 - 15] for diastolic BP. The mean variations in blood pressure between the intraoperative and postoperative period were $7 \mathrm{mmHg}$ for the systolic BP [3 - 25] and $4 \mathrm{mmHg}$ [2 - 12] for the diastolic BP (Figure 14).

\section{Secondary Judgement Criterion (Table 2):}

Three infections requiring drainage occurred and were managed at the patients' bedside. No antibiotics were prescribed. Twenty patients presented wound dehiscence requiring skin care for $>15$ days.

Ten patients presented skin necrosis requiring skin care for $>15$ days despite early treatment with alpha-blockers. There were no cases of facial paralysis (mouth or forehead), but 148 cases of hypoesthesia around the pre-tragal and peri-lobular scar (10\% of patients). There were no cases of numbness in the wider auricular area. Two men developed keloid scars, in the pre-tragal and retro-auricular area, and were treated with scar excision associated with intralesional steroids. Pain VAS was evaluated immediately after and the day after the operation: maximum pain was reported at the start of the infiltration and assessed at 3/10 in 
the pre-tragal and retro-auricular area. The postoperative VAS at D1 was 2/10; patients complained more about a feeling of tension in the face than about pain itself. Concerning imperfections in the result: 10 female patients underwent a supplementary lift at 1 year. These women were all aged over 60 and had loose skin. 


\section{Discussion:}

The principal advantage of local anaesthesia as mentioned above is the cooperation of the patient when the sterile drapes are installed. Patients can also turn their heads to facilitate skin dissection and excision. The absence of intubation also simplifies these procedures and reduces the risk of contamination. In addition, as there is no rigidity between the neck and chin caused by the intubation, the surgery is more precise, notably regarding liposuction under the chin and tightening of the cervical SMAS, and the absence of septic adhesive bandage on the face and neck reduces the risk of contamination of the surgical wound.

Infiltration using a blunt cannula is painless and atraumatic, and the adrenaline gives a bloodless operating field, thus facilitating the dissection $(8,9)$. The liposuction phase creates tunnels, which facilitate the subcutaneous dissection.

The most common complication following facelift surgery is haematoma, and the most critical risk factor that causes haematoma is elevated systolic blood pressure. In general, systolic blood pressure of $<150 \mathrm{~mm} \mathrm{Hg}$ and diastolic blood pressure of $>65 \mathrm{~mm} \mathrm{Hg}$ are recommended. The possible causes of perioperative hypertension are anxiety, epinephrine, pain, postoperative nausea and vomiting (10). Another major advantage of local anaesthesia techniques is the stability of blood pressure during and after the procedure. Indeed, the drugs used in general anaesthesia systematically reduce arterial blood pressure, which is maintained at around $90 \mathrm{mmHg}$. Under local anaesthesia, the patient's blood pressure is maintained at normal levels (generally between 120 and $140 \mathrm{mmHg}$ ). Haemostasis is easier to maintain at blood pressure levels close to the patient's usual arterial blood pressure. Moreover, following local anaesthesia there is no rebound hypertension, which is seen when patients wake up after 
general anaesthesia (weaning off drugs, effort of breathing through a tube). We found a very low proportion of bleeding events $(0.6 \%)$ in this series.

The lowest systolic blood pressure value was $78 \mathrm{mmHg}$ in preoperative stage. This result is considered normal as it was measured after 10 min rest in a decubitus dorsal position. The patient was a female that had a $\mathrm{BMI}=18 \mathrm{~kg} / \mathrm{m} 2$ and was known to have low blood pressure on a daily basis. The highest systolic blood pressure value was $169 \mathrm{mmHg}$ in preoperative stage. This is the measurement of an overweight male patient.

A high systolic blood pressure can cause multiple risks in this surgery:

The diffusion of adrenaline in the systemic blood circulation is related to blood pressure. A patient with hypertension can have adrenaline systemic rush which can cause multiple rhythmic and ischemic heart diseases. On the other hand, the risk of hematoma is higher with an elevated systolic blood pressure. In our series, all patients with a hematoma had a preoperative uncontrolled hypertension.

For these reasons, the patient selection is very important in cosmetic surgery especially in elective facial surgery, giving the intrinsic risk factor of hematoma during the facelift procedure. Therefore, we now only accept patients with a systolic blood pressure below 140 $\mathrm{mmHg}$.

This result is lower than figures reported in the literature, with proportions ranging from $3 \%$ in patients without hypertension to $12,9 \%$ in those with hypertension $(3 ; 11)$. In 1976, Baker et al demonstrated that postoperative hypertension is the main etiologic factor in hematoma formation. Over a 30-year period, the incidence of hematoma requiring surgical evacuation decreased from $8.7 \%$ to $3.97 \%$ after the initiation of a strict perioperative blood pressure control regimen (11). The appearance of a haematoma correlates with postoperative peak blood pressure. Certain authors have proposed using anti-hypertensive agents like 
Clonidine or beta-blockers (Atenolol) to control arterial blood pressure $(3,12)$. The adrenaline injected in the local anaesthesia solution is slowly resorbed and the vasoconstrictive action continues for 4 to 10 hours (8). This long latency reduces bleeding during the peri-operative period, when variations in blood pressure are the most frequent. The early return home to a stress-free, welcoming environment reduces the risk of late rebound hypertension (>10 hours), which is sometimes observed when nurses do their night ward rounds. A massive haematoma can be life-threatening by obstructing the patient's upper airways.

The presence of even a small haematoma can contribute to partial or total necrosis of the skin flap. The skin may also change colour through the fixation of haemoglobin in the subcutaneous tissue. Resorption of a haematoma can leave residual changes of shape and skin texture. All of these phenomena have an impact on the aesthetic result.

Some authors have proposed inserting drains to prevent the development of haematomas. Perkins et al tried to evaluate the rate of hematoma and seroma formation in a series of rhytidectomies performed with and without the use of intrawound vacuum drains. A retrospective chart review was conducted on 222 consecutive face-lifts performed by a single surgeon using an identical surgical technique before and after the use of vacuum wound drains. The review identified hematomas in $8 \%$ of surgeries without vacuum drains and $7 \%$ with vacuum drains. The decrease in hematoma formation did not reach statistical significance (13). This practice has been frequently called into question in recent studies which have shown that drains do not prevent or reduce the risk of haematoma (14). The presence of a drain can lead to complications by facilitating the bacterial contamination of surgical wounds, and can also lead to discomfort and anxiety in patients.

We used a drain without suction in our procedure. It only stayed one day. This was supposed to be useful to drain a hematoma if a mechanical drainage was performed as well. In real terms, it appeared to be useless, since hematoma had to be evacuated during a surgical 
procedure. Therefore, drainage in this context is more an old habit (supposedly, relieving the "stress" of the surgeon) rather than a useful procedure. Regarding the results of our study, drainage won't be used during this surgery anymore. Beside being inefficient to avoid hematoma, it can cause bacterial contamination and patient discomfort.

The use of fibrin-based biological glue was tested to reduce the surgical dead space by sticking the skin flap to deeper tissues, and thereby reducing the risk of haematoma and seroma. Studies have not clearly demonstrated the efficacy of this treatment (15), which carries a risk of viral transmission as the fibrin is a blood product.

Grover et al determined the parameters which were significantly associated with formation of haematoma in a consecutive series of facelifts performed by two high-volume operators. The records of 1078 patients who underwent a facelift between 1994 and 1999 were reviewed: 45 haematomas occurred (4.2\%). Analysis revealed significant associations between haematoma formation and anterior platysmaplasty $(\mathrm{P}=0.009)$, systolic pressure $(\mathrm{P}=$ 0.02), gender $(\mathrm{P}=0.03)$, aspirin or non-steroidal anti-inflammatory intake $(\mathrm{P}=0.04)$ and smoking $(\mathrm{P}=0.049)$. Preoperative hypertension was found to be significantly associated with haematoma following rhytidectomy. This is consistent with the findings of Straith et al who reported a series of 500 facelifts in which 8 patients suffered haematomas that required surgical evacuation (16).

Our study reviewed 1500 facelifts with SMASectomy : dissection, resection, elevation and suture under tension of the SMAS flap. We did not perform anterior platysmaplasty (18), which has been correlated with a higher risk of haematoma (16). The SMAS flap was sutured with Vicryl 3-0 and no purse-string reinforcement was done (17). We only used glue for the skin closure. We are not convinced that glue closures can cause wound dehiscence because the real strength on skin closure comes from sub-cutaneous suture. 
When hematoma was developped, the wound was partially re-openned to evacuate the blood and therefore caused wound dehiscence.

Our surgical technique was a limited skin dissection without additional steps such as submandibular gland resection or platysmoplasty. This type of surgical procedure is possible under local anaesthesia.

The reduction of the number of steps in our surgical technique to only SMASectomy rhytidectomy and cervical liposuction can explain the very low frequency of hematoma in this cohort.

Our philosophy concerning the prevention of haematomas following a cervicofacial lift is to avoid drugs side effects as much as possible. For our team, the procedure is straightforward and quick, and does not require any modification of the patient's usual treatment. Giving patients new drugs, such as premedication, modifies their basal physiological status, and in particular can affect their blood pressure. Preventive intra- and postoperative antihypertensive treatments are not used to avoid rebound hypertension caused by the inevitable withdrawal of these drugs. The simplification of medical treatments, the non-use of fibrin-based biological glue and the absence of general anesthesia make the procedure far simpler.

Patients therefore undergo surgery with their basal physiological blood pressure and with as little pre- intra- and postoperative variation as possible. Patients can return home on the same day free from the side effects of anaesthesia. Convalescence is easier and faster. 


\section{Conclusion}

Cervicofacial lift under local anaesthesia does not radically modify the surgical technique. It enables better control of a patient's arterial blood pressure throughout the surgical procedure and avoids the variations in blood pressure which can cause haematoma. The cooperation of the patient facilitates changes of position and diminishes the risk of contamination induced by intubation. Moreover, the absence of an endotracheal tube makes the surgery easier. Finally, the absence of multiple general anaesthesia agents: hypnotics, morphine and neuromuscular blocking agents, means that patients can return home quickly and safely thus accelerating convalescence.

There is no Conflict of Interest or Funding for this work. 


\section{REFERENCES}

1. Narurkar VA, Cohen JL, Dayan S, Kaminer MS, Rivkin A, Shamban A, et al. A Comprehensive Approach to Multimodal Facial Aesthetic Treatment: Injection Techniques and Treatment Characteristics From the HARMONY Study. Dermatol Surg Off Publ Am Soc Dermatol Surg Al. 2016 May;42 Suppl 2:S177-191.

2. Wan D, Small KH, Barton FE. Face Lift: Plast Reconstr Surg. 2015 Nov;136(5):676e-689e.

3. Ramanadham SR, Mapula S, Costa C, Narasimhan K, Coleman JE, Rohrich RJ. Evolution of hypertension management in face lifting in 1089 patients: optimizing safety and outcomes. Plast Reconstr Surg. 2015 Apr;135(4):1037-43.

4. Kleinberger AJ, Spiegel JH. What is the best method for minimizing the risk of hematoma formation after rhytidectomy? The Laryngoscope. 2015 Mar;125(3):534-6.

5. Wan D, Small KH, Barton FE. Face Lift: Plast Reconstr Surg. 2015 Nov;136(5):676e-689e.

6. Rohrich RJ, Narasimhan K. Long-Term Results in Face Lifting: Observational Results and Evolution of Technique. Plast Reconstr Surg. 2016 Jul;138(1):97-108.

7. Beer GM, Spicher I, Seifert B, Emanuel B, Kompatscher P, Meyer VE. Oral premedication for operations on the face under local anesthesia: a placebo-controlled double-blind trial. Plast Reconstr Surg. 2001 Sep 1;108(3):637-43.

8. Klein JA. Tumescent technique for local anesthesia. West J Med. 1996 Jun;164(6):517.

9. Noël B. [Tumescent local anesthesia]. Rev Med Suisse. 2010 Apr 28;6(246):875-8.

10. Chung KH, Cho MS, Jin H. Perioperative Hypertension Management during Facelift under Local Anesthesia with Intravenous Hypnotics. Arch Plast Surg. 2017 Jul;44(4):276-82.

11. Baker DC, Stefani WA, Chiu ES. Reducing the incidence of hematoma requiring surgical evacuation following male rhytidectomy: a 30-year review of 985 cases. Plast Reconstr Surg. 2005 Dec;116(7):1973-85; discussion 1986-1987.

12. Moreira AC, Moreira M, Gurgel SJT, Moreira YC, Martins ER, Hartmann RCB, et al. Atenolol prevents the formation of expansive hematoma after rhytidoplasty. Rev Col Bras Cir. 2014 Oct;41(5):305-10.

13. Perkins SW, Williams JD, Macdonald K, Robinson EB. Prevention of seromas and hematomas after face-lift surgery with the use of postoperative vacuum drains. Arch Otolaryngol Head Neck Surg. 1997 Jul;123(7):743-5.

14. Jones BM, Grover R, Hamilton S. The efficacy of surgical drainage in cervicofacial rhytidectomy: a prospective, randomized, controlled trial. Plast Reconstr Surg. 2007 Jul;120(1):26370 .

15. Killion EA, Hyman CH, Hatef DA, Hollier LH, Reisman NR. A systematic examination of the effect of tissue glues on rhytidectomy complications. Aesthet Surg J. 2015 Mar;35(3):229-34.

16. Grover R, Jones BM, Waterhouse N. The prevention of haematoma following rhytidectomy: a review of 1078 consecutive facelifts. Br J Plast Surg. 2001 Sep;54(6):481-6.

17. van der Lei B, Cromheecke M, Hofer SOP. The purse-string reinforced SMASectomy short scar facelift. Aesthet Surg J. 2009 Jun;29(3):180-8. 
18. Feldman JJ. Corset platysmaplasty. Plast Reconstr Surg. 1990 Mar;85(3):333-43. 
Figure

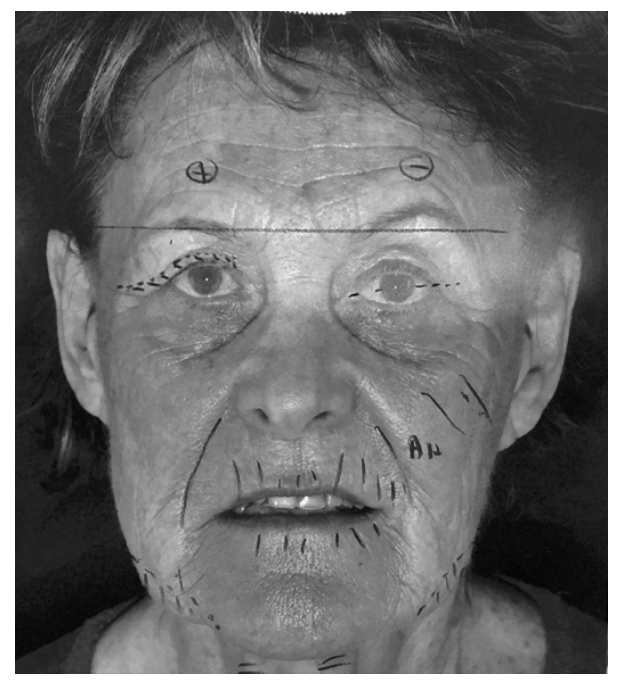

Figure 1: Preoperative marking
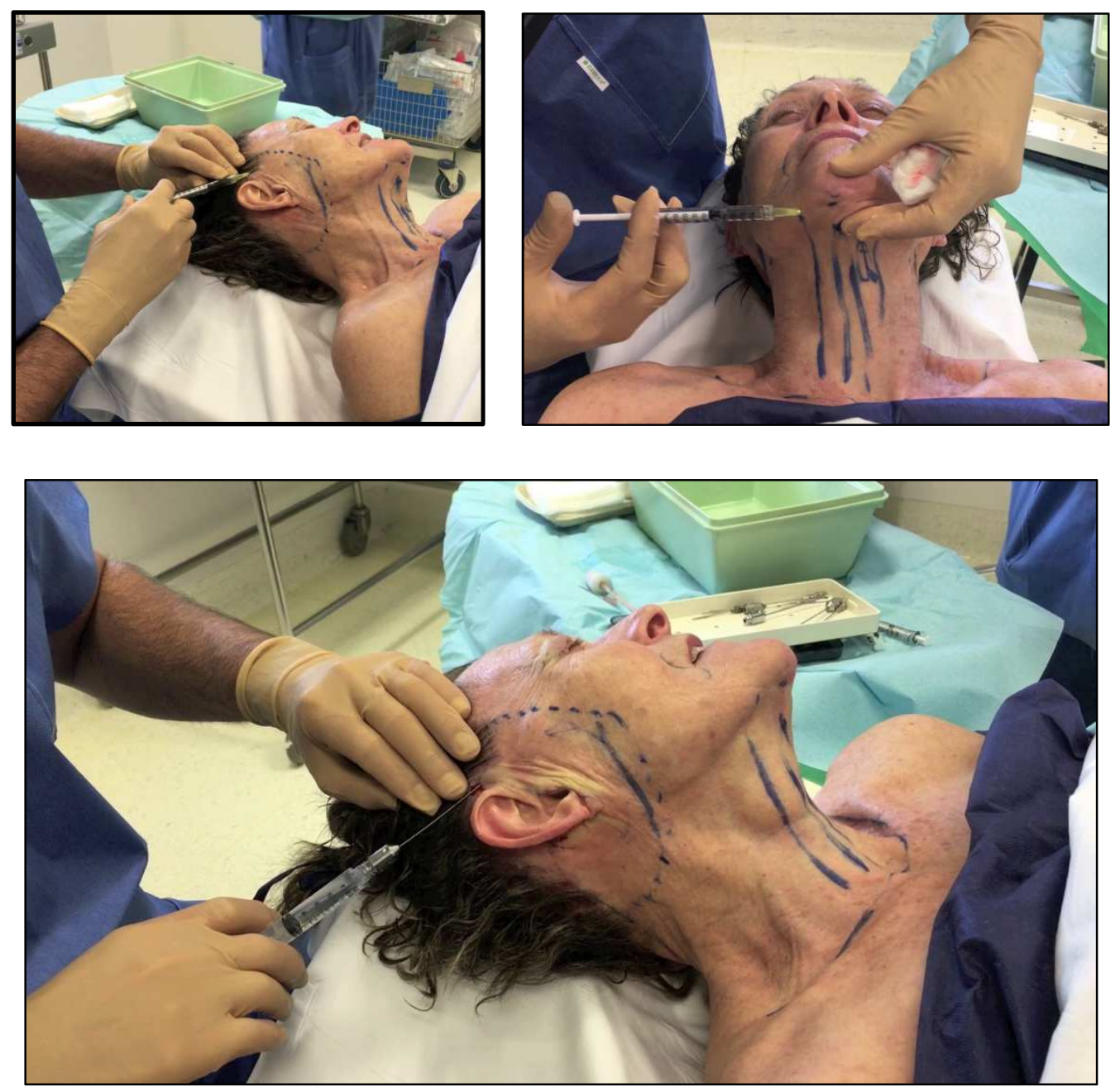

Figures 2, 3 and 4: Infiltration of local anesthesia 


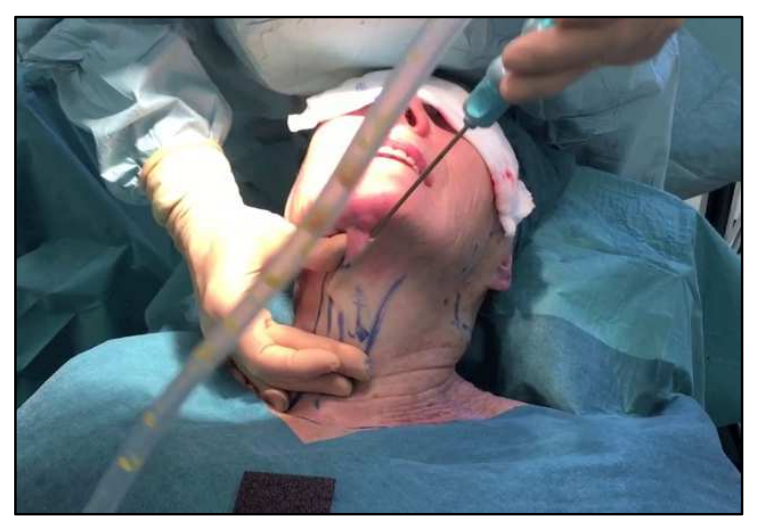

Figure 5: Liposuction under the chin and in the neck
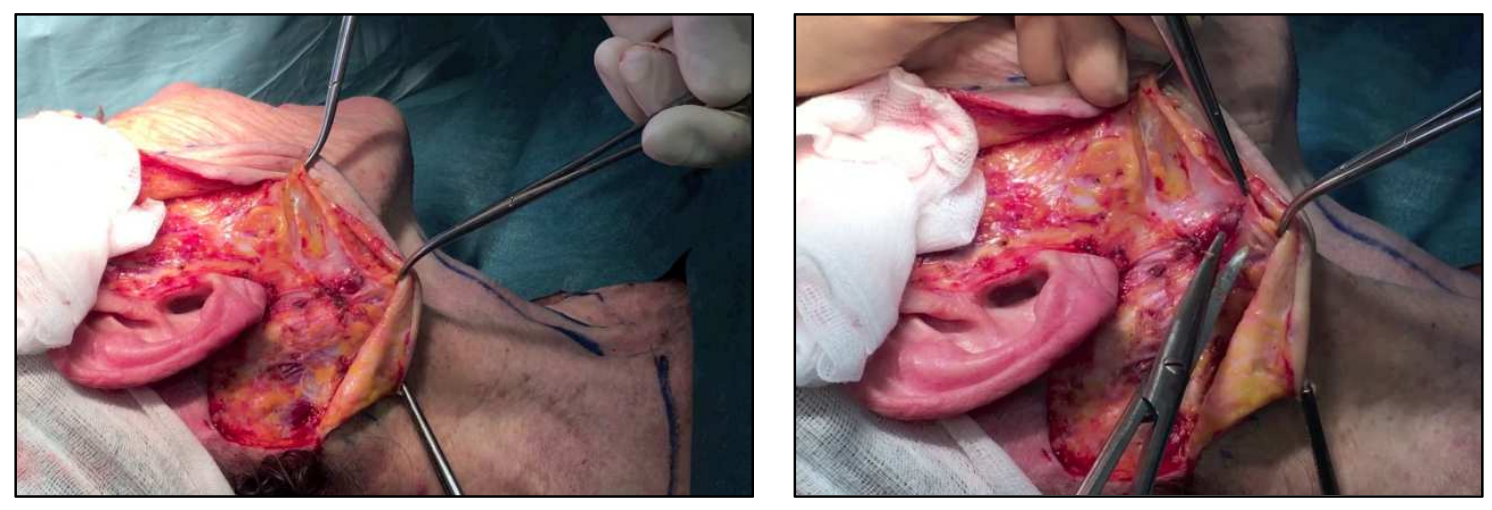

Figure 6-7: Dissection of the SMAS

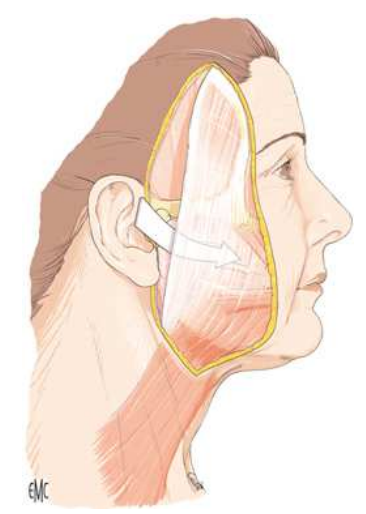

Figure 8: Undermining the SMAS 

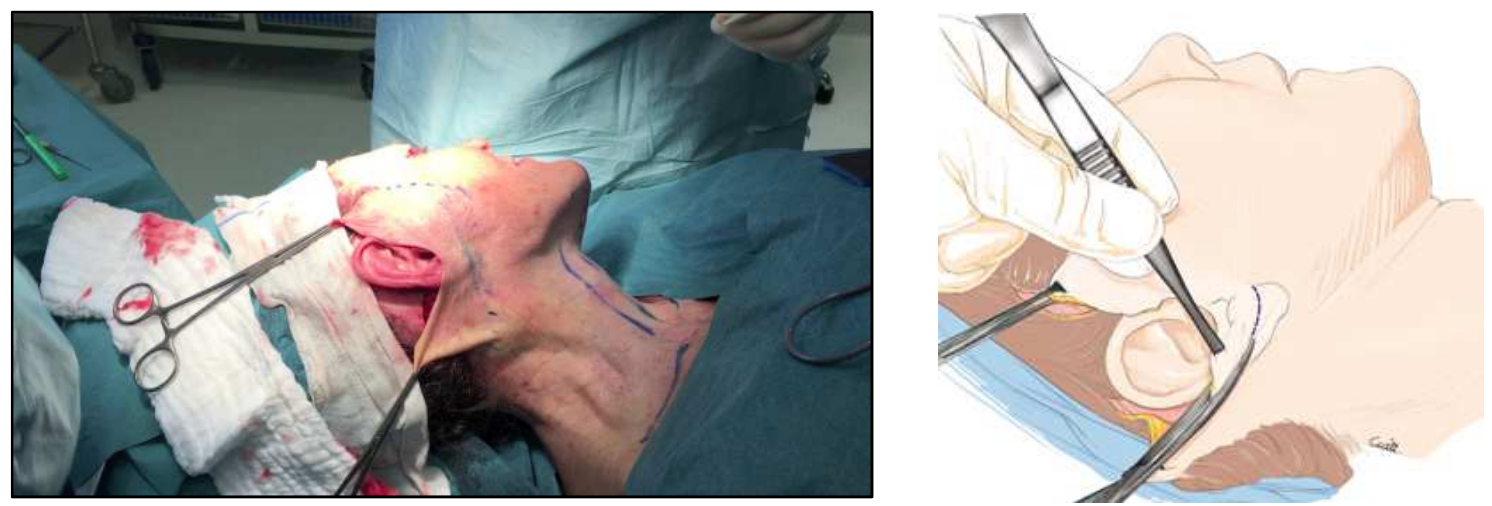

Figure 9 and 10: Resection of the excess skin
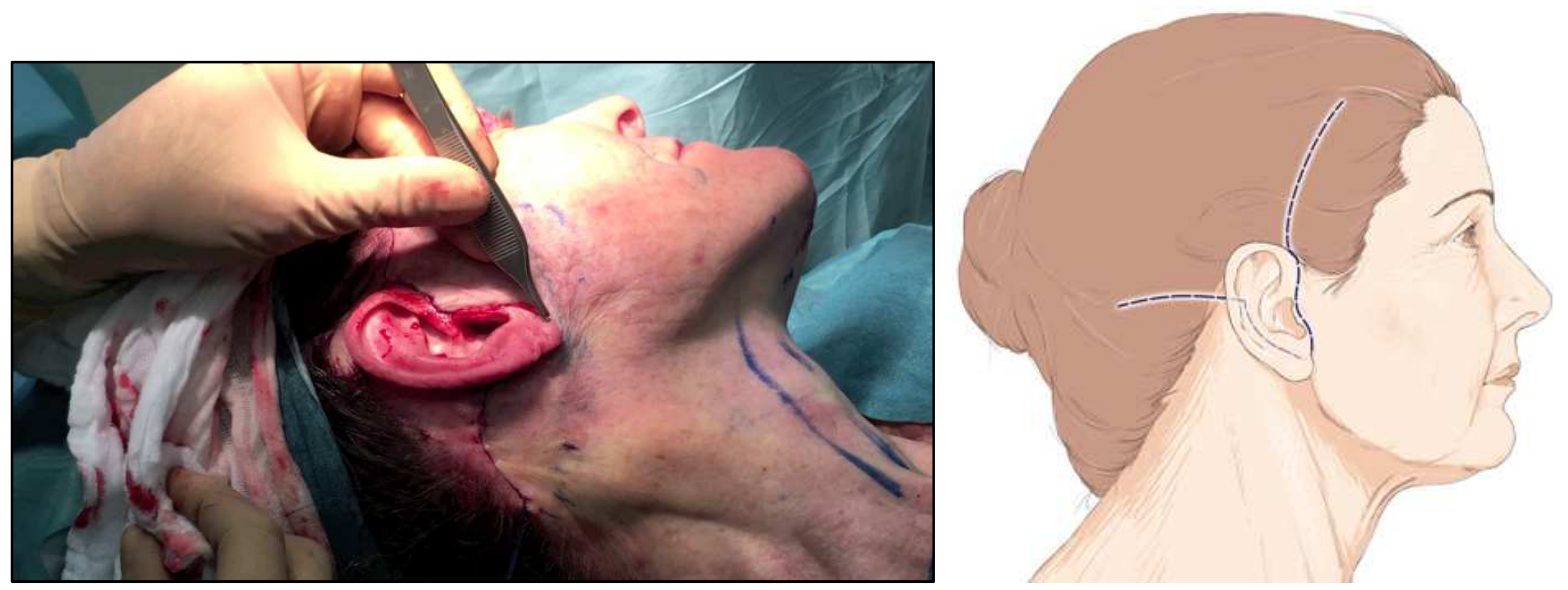

Figure 11 and 12: Skin sutures

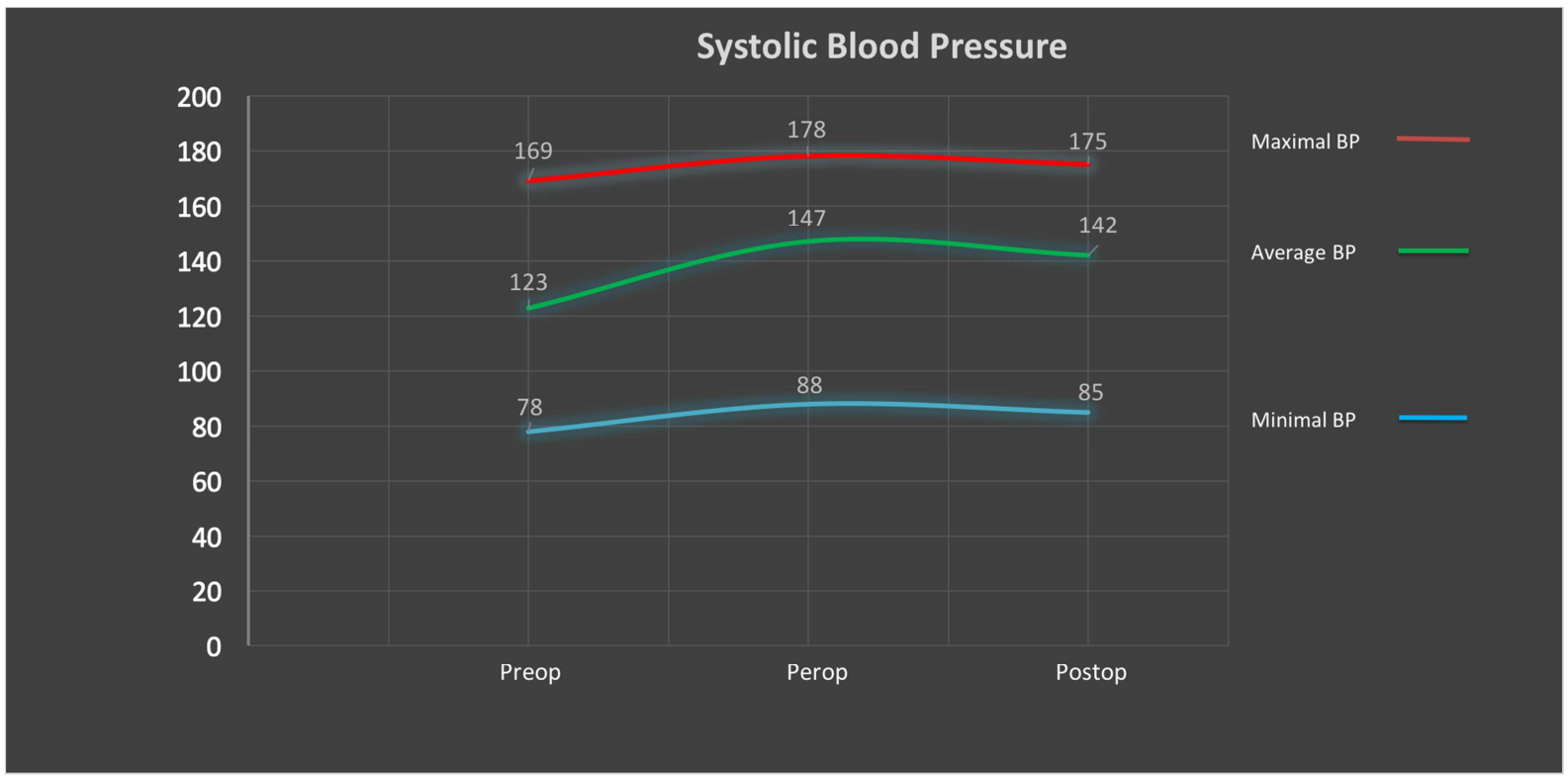

Figure 13 : Systolic blood pressure during facelift $(\mathrm{mmHg})$ 


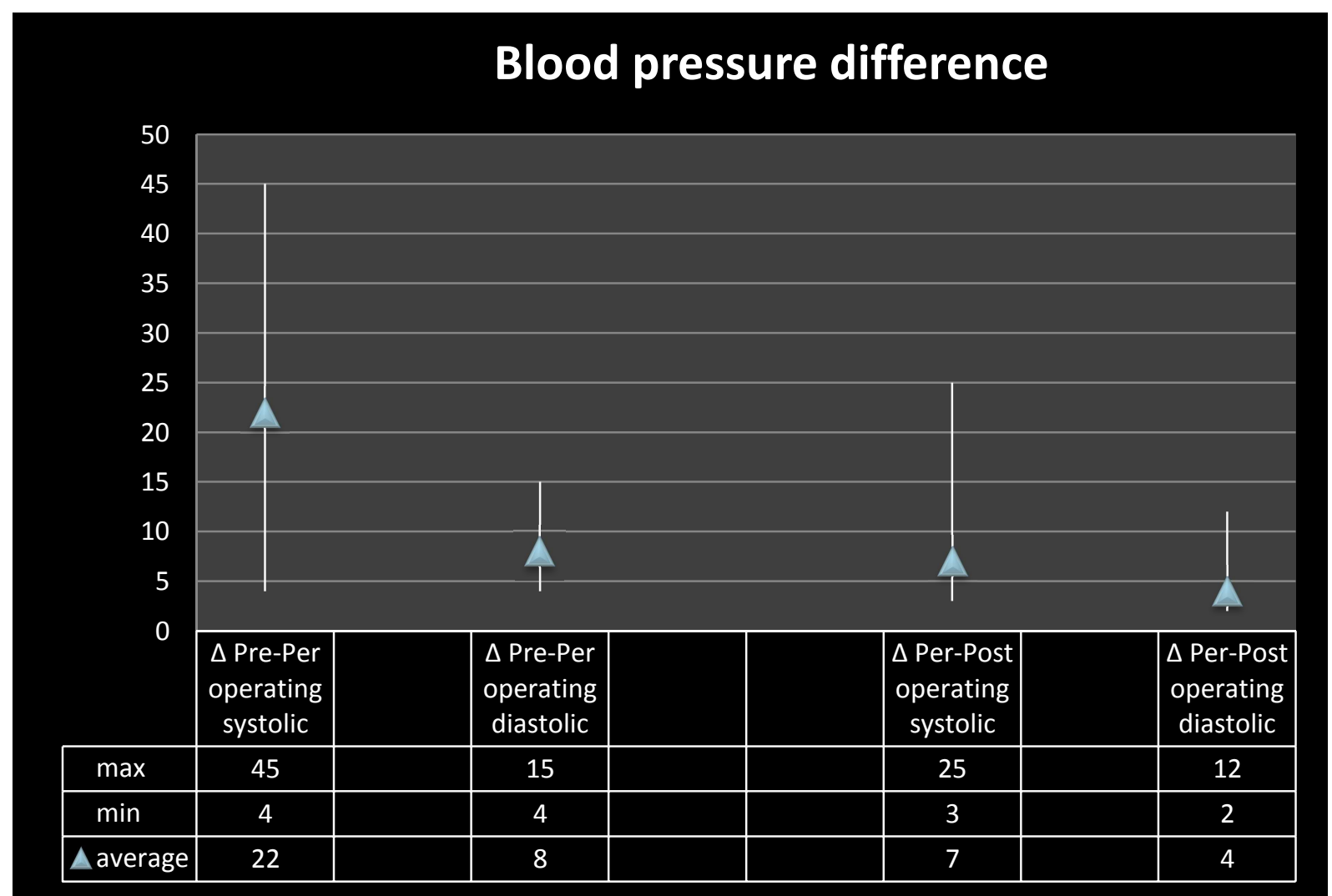

Figure 14: Comparison of preoperative, peroperative and postoperative systolic and diastolic blood pressure $(\mathrm{mmHg})$ 


\begin{tabular}{|c|c|}
\hline Characteristic & Data \\
\hline $\begin{array}{l}\text { Women } \\
\text { Men }\end{array}$ & $\begin{array}{l}1350 \\
150\end{array}$ \\
\hline $\begin{array}{l}\text { Mean } \\
\text { Range }\end{array}$ & $\begin{array}{l}58 \text { years } \\
{[40-69]}\end{array}$ \\
\hline $\begin{array}{r}\text { BMI }\left(\mathbf{k g} / \mathbf{m}^{2}\right) \\
\text { Mean } \\
\text { Range }\end{array}$ & $\begin{array}{l}26 \\
{[19-31]}\end{array}$ \\
\hline $\begin{array}{c}\text { Comorbidities } \\
\text { Hypertension } \\
\text { Diabetes }\end{array}$ & $\begin{array}{l}311 \\
120\end{array}$ \\
\hline $\begin{array}{l}\text { Smoking } \\
\text { Active }\end{array}$ & 510 \\
\hline
\end{tabular}

Table 1: Patient characteristics:

\begin{tabular}{|l|r|r|}
\hline Complications & Number & $\%$ \\
\hline Dehiscence & 20 & 1.3 \\
\hline Skin necrosis & 11 & 0.7 \\
\hline Infection & 3 & 0.2 \\
\hline Facial paralysis & 0 & 0 \\
\hline Hypoesthesia lobe & 148 & 10 \\
\hline Keloid & 2 & 0.13 \\
\hline Imperfections & 10 & 0.7 \\
\hline
\end{tabular}

Table 2: Complications after facelift under local anesthesia 